\title{
Clinical Outcome of Chest Physical Therapy for Patients undergoing Home Oxygen Therapy
}

\author{
Minako Tamechika ${ }^{1)}$, Motoyuki Abe1), Kazuyuki Tabira ${ }^{2)}$, Noriko Sekikawa ${ }^{2)}$, \\ Osamu Yoshimura ${ }^{3)}$, Kiyomi Takayanagi ${ }^{3)}$, Sachiko TANAKA ${ }^{3)}$ \\ 1) Department of Rehabilitation Medicine, Mitsui Omuta Hospital, 1-100 Tenryomachi, \\ Omutashi, Fukuoka 836-0054, Japan. TEL +81 944-54-8482 \\ ${ }^{2)}$ Department of Rehabilitation Medicine, Yoshijima Hospital \\ ${ }^{3)}$ Institute of Health Sciences, Hiroshima University School of Medicine
}

\begin{abstract}
Chest physical therapy (CPT) is important to introduce and continue home oxygen therapy (HOT) of patients with chronic pulmonary disease. We examined the effects of CPT for twenty-five patients undergoing HOT. To compare the effects of CPT for HOT patients and non-CPT, we evaluated respiratory rate (RR), tidal volume $\left(\mathrm{V}_{\mathrm{T}}\right)$, rapid shallow breathing (RSB) index, muscle contraction of diaphragm and scalenus muscles while breathing (muscle contraction pattern while breathing), six minutes walk distance $(6 \mathrm{MD})$, Borg scale, rate of change of oxygen saturation $(\Delta \mathrm{SpO} 2)$ and heart rate (\%HRmax) during 6MD, activities of daily living (ADL), and mood disorder. Our results show that $\mathrm{V}_{\mathrm{T}}$, RSB index and the Borg scale were significantly better in the CPT group. These results show the efficacy of CPT for HOT patients to maintain their respiratory function.
\end{abstract}

Key words: Home oxygen therapy, Chest physical therapy, Chronic pulmonary disease.

(This article was submitted Nov. 21, 1997, and was accepted Feb. 20, 1998)

\section{INTRODUCTION}

It is generally accepted that home oxygen therapy (HOT) reduces mortality rate and improves quality of life (QOL) for respiratory insufficiency patients. Two large studies of the Nocturnal Oxygen Therapy Trial (NOTT) in USA in 1980'1) and the British Medical Research Council trial (MRC trial) in 19812), showed many clinical advantages of HOT for patients.

In Japan, HOT has been rapidly introduced under the application of health insurance since 1985. According to the reports of the respiratory insufficiency studies group of Japanese Ministry of Health and Welfare, the number of patients receiving HOT in Japan reached about 23,000 in 1991 and is now 40,000 over.

Pulmonary rehabilitation that is chest physical therapy (CPT) such as breathing retraining and therapeutic exercise is very important to the introduction and maintainance of HOT. Many studies have reported the effects of intensive CPT for patients with chronic respiratory insufficiency, but studies about the effects of CPT for patients undergoing HOT are very few.

The purpose of this study was to investigate the effects of CPT for HOT patients at the time of HOT introduction, to clarify the differences in effect between a CPT group and a non-CPT group, and to determine how to perform CPT effectively.

\section{SUBJECTS}

Twenty-five outpatients with HOT (13 males, 12 females, mean age 68.4 years) who had been thoroughly evaluated were selected for this study. Their underlying disease, age, degree of dyspnea (Hugh- 
Jones) and lung function status are shown in Table 1.

We divided the subjects into two groups: fifteen CPT patients and ten non-CPT patients. The CPT group consisted of seven pulmonary tuberculosis patients, four pulmonary emphysema patients and four bronchiectasis patients. The non-CPT group consisted of seven pulmonary tuberculosis patients and three pulmonary emphysema patients. There were no significant differences between the two groups in Hugh-Jones, age, \%VC, $\mathrm{FEV}_{1.0} \%, \mathrm{PaO}_{2}$ and $\mathrm{PaCO}_{2}$.

\section{METHOD}

To evaluate breath condition, we measured respiratory rate $(\mathrm{RR})$, tidal volume $\left(\mathrm{V}_{\mathrm{T}}\right), \mathrm{RSB}$ (rapid shallow breathing) index and muscle contraction of the diaphragm and scalenus muscles while breathing (muscle contraction pattern while breathing). This muscle contraction pattern while breathing was classified into five degrees. It was evaluated in the supine position by classification of diaphragmatic breathing by graded contraction of the diaphragm and scalenus muscles (Table 2). RR was measured with palpation in the sitting position and $\mathrm{V}_{\mathrm{T}}$ was measured by a light respirometer (Japan BOC Co LTD). The RSB index was obtained from following formula:

$\mathrm{RSB}$ index $=\mathrm{RR}$ (breaths $/ \mathrm{min}$ ) $/ \mathrm{V}_{\mathrm{T}}$ (l)

Exercise endurance was determined by measuring the six minutes walking distance (6MD). We ordered patients to walk as far as possible during six minutes. At the same time, we continuously measured $\mathrm{SpO}_{2}$ (oxygen saturation by pulse oximeter) and heart rate (HR) using a pulse oximeter (Amuko Co LTD). We also evaluated subjects' subjective endurance using the Borg scale at the end of the 6MD exercise. Rate of change of $\mathrm{SpO}_{2}$ $\left(\Delta \mathrm{SpO}_{2}\right)$ during walking $(6 \mathrm{MD})$ was calculated from following formula:

$\Delta \mathrm{SpO}_{2}=\mathrm{SpO}_{2}$ at rest-minimum $\mathrm{SpO}_{2}$ during exercise $/ \mathrm{SpO}_{2}$ at rest

$\%$ HRmax was calculated by Karvonen's formula ${ }^{3)}$.

We used a particular ADL test for patients with respiratory insufficiency which was modified for

Table 1. Physical characteristics of subjects

\begin{tabular}{|c|c|c|c|}
\hline & & CPT group $(n=15)$ & non-CPT group $(\mathrm{n}=10)$ \\
\hline \multicolumn{4}{|l|}{ underlying disease (n) } \\
\hline pulmonary tuberculosis & & 7 & 7 \\
\hline pulmonary emphysema & & 4 & 3 \\
\hline bronchiectasis & & 4 & 0 \\
\hline \multicolumn{4}{|l|}{ grading of Hugh-Jones (n) } \\
\hline & II & 1 & 1 \\
\hline & III & 10 & 6 \\
\hline & IV & 4 & 2 \\
\hline & V & 0 & 1 \\
\hline age (years) & & $67.7 \pm 6.4$ & $69.4 \pm 7.7$ \\
\hline$\% \mathrm{VC}(\%)$ & & $58.4 \pm 17.8$ & $69.5 \pm 32.6$ \\
\hline $\mathrm{FEV}_{1.0} \%(\%)$ & & $55.0 \pm 14.7$ & $59.1 \pm 26.6$ \\
\hline $\mathrm{PaO}_{2}(\mathrm{mmHg})$ & & $70.2 \pm 17.8$ & $86.1 \pm 33.6$ \\
\hline $\mathrm{PaCO}_{2}(\mathrm{mmHg})$ & & $56.7 \pm 7.9$ & $51.4 \pm 13.7$ \\
\hline
\end{tabular}

The chest physical therapy (CPT) and non-CPT group were not significantly different with respect to any of these variables.

Table 2. Classification of diaphragmatic breathing graded by contraction of diaphragm and scalenus muscles (muscle contraction pattern while breathing)

\begin{tabular}{cl}
\hline grade & \multicolumn{1}{c}{ The pattern of contraction of diaphragm and scalenus muscles } \\
\hline 5 & Diaphragm only contracts \\
4 & After diaphragm contracts, scalenus muscles contract at the end of inspiration \\
3 & Diaphragm and scalenus muscles contract in concurrence \\
2 & After scalenus muscles contract, diaphragm contracts \\
1 & Scalenus muscles only contract \\
\hline
\end{tabular}


outpatient clinic use only. This ADL test consisted of ten items of ADL (feeding, toiletting, grooming, bathing, dressing, walking indoors, climbing stairs, carrying luggage and moderate exercise) and continuous walking distance. The walking points depended on walking distance $(0,2,4,8,10$ points). Furthermore these ten ADL items were divided into three subcategories, that is, speed of activity ( $0-3$ points), degree of respiratory embarrassment ( $0-3$ points) and flow volume of oxygen per minute ( $0-3$ points). The ADL score amounted to 100 points at its maximum.

Mood disorder was evaluated by the Self-Rating Depression Scale (SDS) and Manifest Anxiety Scale (MAS). SDS consisted of twenty questions. The total score was eighty points in maximum over twenty points in minimum. Patients who marked fifty points or more were diagnosed as likely in a state of depression. From MAS points, their anxieties were graded into five stages (stage I, strong anxiety; stage II, moderate anxiety; stage III-V, normal).
Arterial blood gas analysis $\left(\mathrm{PaO}_{2}, \mathrm{PaCO}_{2}\right)$ and lung function test $\left(\% \mathrm{VC}, \mathrm{FEV}_{1.0} \%\right)$ were obtained from the most recent clinical data.

\section{Data analysis}

In comparison, statistics analysis was done with Wilcoxon signed-ranks test for muscle contraction pattern while breathing, and with the unpaired ttest for the other items.

\section{RESULTS}

$\mathrm{V}_{\mathrm{T}}$ was significantly greater in the CPT group $(\mathrm{p}<0.05)$ than in the non-CPT group, and its mean values and SD were $496.6 \pm 182.0 \mathrm{ml}$, and $313.3 \pm$ $136.0 \mathrm{ml}$, respectively (Table 3 ). The RSB index was significantly lower in the CPT group $(\mathrm{p}<0.05)$ compared with the non-CPT group, and its mean values and SD were 45.4 \pm 23.0 , and $80.4 \pm 40.0$ respectively. RR at rest was slightly less in the CPT group than in the non-CPT group, and its mean values and SD were $19.6 \pm 4.6$ breaths/min,

Table 3. Comparison of items of measurement between CPT group and non-CPT group

\begin{tabular}{|c|c|c|}
\hline & CPT group & non-CPT group \\
\hline RR (breath/min) & $19.6 \pm 4.6$ & $21.3 \pm 2.0$ \\
\hline $\mathrm{V}_{\mathrm{T}}(\mathrm{ml})$ & $496.6 \pm 182.0-*$ & $-313.3 \pm 136.0$ \\
\hline RSB index & $45.4 \pm 23.0-*$ & $-80.4 \pm 40.0$ \\
\hline muscle contraction pattern while breathing (n) & & \\
\hline grade 2 & 3 & 2 \\
\hline 3 & 7 & 7 \\
\hline 4 & 5 & 1 \\
\hline \multicolumn{3}{|l|}{$6 \mathrm{MD}$} \\
\hline distance $(\mathrm{m})$ & $271.7 \pm 82.0$ & $319.5 \pm 45.5$ \\
\hline Borg scale & $3.4 \pm 0.8-*$ & $-4.3 \pm 1.1$ \\
\hline$\Delta \mathrm{SpO}_{2}(\%)$ & $4.8 \pm 5.8$ & $4.8 \pm 2.1$ \\
\hline$\%$ HRmax $(\%)$ & $23.4 \pm 22.1$ & $22.9 \pm 17.7$ \\
\hline ADL score & $54.9 \pm 12.6$ & $61.6 \pm 8.5$ \\
\hline \multicolumn{3}{|l|}{ MAS } \\
\hline stage I & 6 & 3 \\
\hline II & 1 & 4 \\
\hline III & 8 & 3 \\
\hline \multicolumn{3}{|l|}{ SDS } \\
\hline normal & 11 & 9 \\
\hline depression & 4 & 1 \\
\hline
\end{tabular}

$\mathrm{RR}=$ respiratory rate, $\mathrm{V}_{\mathrm{T}}=$ tidal volume, $\mathrm{RSB}$ index=rapid shallow breathing index, $6 \mathrm{MD}=$ six minutes walk distance, $\mathrm{MAS}=$ manifest anxiety scale, $\mathrm{SDS}=$ self-rating depression scale. There were significant differences between chest physical therapy (CPT) and non-CPT group with $\mathrm{V}_{\mathrm{T}}$, RSB index and Borg scale at the end of $6 \mathrm{MD}$ exercise. CPT group exceeded non-CPT group in these respects. 
and $21.3 \pm 2.0$ breaths/min respectively. In the muscle contraction pattern while breathing, the modal value was grade 3 (diaphragm and scalenus muscles contract in concurrence) in both groups. Five patients of the fifteen CPT patients, and one patient of the ten non-CPT patients were classified as grade 4 (after diaphragm contracts, scalenus muscles contracts at the end of inspiration), which showed a good muscle contraction pattern while breathing for the CPT group. But, there were no significant differences in RR and muscle contraction pattern while breathing between the two groups.

The 6MD was shorter in the CPT group than in the non-CPT group, and its mean values and SD were $271.7 \pm 82.0 \mathrm{~m}$, and $319.5 \pm 45.5 \mathrm{~m}$ respectively. $\mathrm{SpO}_{2}$ during $6 \mathrm{MD}$ decreased in both groups by about $5 \% \Delta \mathrm{SpO}_{2}$. For \%HRmax, the CPT group and the non-CPT group were almost the same during 6MD, and the mean values and SD were $23.4 \pm$ $22.1 \%$, and $22.9 \pm 17.7 \%$ respectively. There were no significant differences in the $6 \mathrm{MD}, \Delta \mathrm{SpO}_{2}$ and $\%$ HRmax between the CPT group and the nonCPT group. A low Borg scale expresses better subjective endurance generally, and the Borg scale at the end of $6 \mathrm{MD}$ was significantly lower in the CPT group $(p<0.05)$. The mean values and SD were $3.4 \pm 0.8$ in the CPT group and $4.3 \pm 1.1$ in the non-CPT group.

The ADL score was lower in the CPT group than in the non-CPT group, but there was no significant difference. The mean values and SD of the ADL scores were $54.9 \pm 12.6$ points in the CPT group and $61.6 \pm 8.5$ points in the non-CPT group.

For mood disorder, MAS and SDS showed no differences between the CPT group and the nonCPT group. Regarding MAS stages I and II occupied about $46 \%$ in the CPT group, and $70 \%$ in the non-CPT group. The number of depression patients diagnosed by SDS were four out of fifteen CPT patients, and one out of ten non-CPT patients.

\section{DISCUSSION}

Chest physical therapy for HOT patients at the time of HOT introduction had beneficial effects on $\mathrm{V}_{\mathrm{T}}$, RSB index and Borg scale at the end of the 6MD exercise, but did not affect other items.

Kozu, et al.4) reported that good respiratory muscles function improved ability of vesicular oxygenation and lung function. These factors lead to the reduction of dyspnea, increase of exercise endur- ance and improvement of ADL. Other authors ${ }^{5) 6}$ carried out breathing exercises, such as techniques of breathing and strengthening the respiratory muscles in patients with chronic obstructive pulmonary disease. Particularly, pursed lip breathing lowers respiratory rate and increases the depth of each breath. It helps to improve oxygen transfer across the lung and also to mitigate dyspnea during exercise. In this study, muscle contraction pattern while breathing tended to improve in the CPT group. From the foregoing, the reason why $\mathrm{V}_{\mathrm{T}}$ increased in the CPT group might be the acquiring of techniques of good breathing, such as diaphragmatic breathing and pursed lip breathing, by CPT.

The higher the RSB index is, the slower and deeper respiration is. This index was calculated with $V_{T}$ and $R R$, so a higher volume of $V_{T}$ in the CPT group led to a lower RSB index.

The Borg scale at the end of 6MD exercise was significantly lower in the CPT group than in the non-CPT group. Subjective endurance like the Borg scale, relates with the grade of dyspnea during exercise for respiratory insufficiency patients. Dyspnea during exercise might be reduced in the CPT group because patients had acquired efficient breathing techniques by CPT.

On the other hand, there were no beneficial effects on $6 \mathrm{MD}$, ADL score and mood disorder in this study.

Kitagawa, et al. ${ }^{7)}$ reported that intensive CPT for patients with chronic respiratory disease had the beneficial effects of significantly improving $\% \mathrm{VC}$, $\mathrm{PaO}_{2}, 6 \mathrm{MD}$ and ADL score. Many other authors have reported the same conclusions ${ }^{8) 9}$. We postulate that there are two reasons why our study didn't reveal any significant differences between the CPT and non-CPT groups in exercise endurance, ADL and mood disorder. The first reason is lack of sufficient therapeutic exercise, and education and instruction of ADL and mental supports.

Kida, et al. ${ }^{10) 11)}$ reported on the comparison of details of pulmonary rehabilitation between Japan and the USA. These reports showed that pulmonary rehabilitation had been carried out in $55.6 \%$ of 178 medical facilities in USA, and at only $20.4 \%$ of 415 medical facilities in Japan. Gait exercise, education of ADL and mental supports had been as frequent as breathing exercise in the USA. On the other hand, in Japan, breathing exercise had been mainly carried out, but gait exercise and education of ADL had hardly been performed, and 
mental supports rarely. Therapeutic exercise and education of patients about breathing pattern, ADL and their diseases status might be necessary to improve exercise endurance, ADL and mood disorder.

Secondarily, improvements of exercise endurance, ADL and mood disorder were not maintained by outclinic CPT only. We supposed that CPT patients might have expected improvements right after the time of HOT introduction.

Vale, et al. ${ }^{12)}$ reported that exercise endurance and QOL were improved by twice weekly outclinic CPT, whereas our subjects accepted outclinic CPT once every three months on average. It is difficult to maintain and to improve patients' functions by outclinic CPT alone.

HOT patients tend to be confined to their home after leaving hospital because of insufficiency of their endurance and the lack of recognition of HOT in society and their families. Therefore their activities were lower, and this decline might lead to a state of anxiety and depression.

We postulate that home exercise is very important to maintain and to improve patients' function, and to carry out effective home exercise, we have to make a home rehabilitation program according to patients' ability and environment, instructing them how to perform.

\section{CONCLUSIONS}

In this study, CPT at the time of HOT introduction improved $\mathrm{V}_{\mathrm{T}}$, RSB index and Borg scale at the end of 6MD significantly, but didn't improve exercise endurance, ADL and mood disorder. From these results, we consider that we should carry out more intensive CPT at the time of HOT introduction and sufficiently encourage home exercise to maintain lung function and ADL for prolonging life.

\section{REFERENCES}

1) Report of the Medical Research Council Oxygen Working Party: Long-term domiciliary oxygen therapy in chronic hypoxic cor pumonale complicating chronic bronchitis and emphysema. Lancet 1: 681-685, 1981.

2) Nocturnal Oxygen Therapy Trial Group: Continuous or nocturnal oxygen therapy in hypoxic chronic obstructive lung disease. Ann Intern Med 93: 391-398, 1980.

3) Karvonen J, et al: Heart rate and exercise intensity during sports activities. Practical application. Sports Medicine 5: 303-312, 1988.

4) Kozu R, et al: Effects of intensive chest physical therapy on patients with chronic lung disease -difference according to ventilatory disorder and dyspnea level-. J Exerc Physiol 9: 203-210, 1994 (in Japanese).

5) Mueller R, et al: Ventilation and arterial blood gas changes included by pursed lips breathing. J Appl Physiol 28: 784-789, 1970.

6) Tiep B, et al: Pursed lip breathing training using ear oximeter. Chest 90: 218-221, 1986.

7) Kitagawa C, et al: Total evaluation and long-term effect of chest physical therapy. Bull Sch Allied Med Sci, Nagasaki Univ 5: 105-111, 1991 (in Japanese).

8) Foster S, et al: Pulmonary rehabilitation in lung disease other than chronic obstructive pulmonary disease. Am Rev Respir Dis 141: 601-604, 1990.

9) Niederman $\mathrm{M}$, et al: Benefits of multidisciplinary pulmonary rehabilitation program. Chest 99: 798-804, 1991.

10) Kida K, et al: Pulmonary rehabilitation program survey in North America and Europe. Am J Respir Crit Care Med 153: A 781, 1996.

11) Kida K, et al: Pulmonary rehabilitation program survey in Tokyo. Am J Respir Crit Care Med 153: A $781,1996$.

12) Vale F, et al: The long-term benefits of outpatient pulmonary rehabilitation on exercise endurance and quality of life. Chest 103-1: 42-45, 1993. 